\title{
Analyzing Barriers for People with Hearing Loss on the Web: A Semiotic Study
}

\author{
Marta Angélica Montiel Ferreira ${ }^{1}$ and Rodrigo Bonacin ${ }^{1,2}$ \\ ${ }^{1}$ FACCAMP, Rua Guatemala, 167, 13231-230, Campo Limpo Paulista, SP, Brazil \\ ${ }^{2}$ Center for Information Technology Renato Archer - Rodovia Dom Pedro I, km 143,6, \\ 13069-901, Campinas, SP, Brazil \\ zmontdefer@gmail.com, rodrigo.bonacin@cti.gov.br
}

\begin{abstract}
The correct interpretation of Web content by users is a major condition for an effective and accessible Web. However, many people with hearing loss have difficulties interpreting long and complex texts. In this work, we investigated barriers in the usage of Web systems by users with hearing loss. A participatory study with 21 users with hearing loss was conducted in the city of Macapá in Brazil. All the participants use internet frequently, but have different profiles, and reading and writing skill levels. Artifacts and methods from Organizational Semiotics were employed in the elicitation and analysis of problems, barriers, as well as solutions with the participants. The results provide alternatives that range from simple design directives to solutions that demand further research.
\end{abstract}

Keywords: Universal Usability, Accessibility, Organizational Semiotics, Universal Design.

\section{Introduction}

Universal usability presupposes a high rate of successful users of information and communication services [1]. People with singular impairments have various usage barriers on the web, including perceptual, cognitive, and social ones. In this sense, universal usability goes beyond providing means of access and devices for sensorial perception. We assumed that a usable Web requires that users be able to perform meaningful interactions, including the interpretation of content, and the ability to socially interact with other users.

Nowadays, approximately $10 \%$ of the population worldwide suffers from hearing loss [2]. A person with total hearing impairment can be understood as someone who is not able to understand the spoken language, regardless of amplification devices. Often, people that are born with hearing loss, or have high levels of hearing impairment since their early years of life, have difficulty reading and using the written language to express themselves. There are multidisciplinary studies that explore alternatives for how to teach the written language to people that already know sign language. Despite advances in teaching practices, in fact, the level of comprehension of the written language amongst people with hearing loss varies from person to person. 
Nowadays, although there is a large amount of visual information on the web, the predominant mean of communication is still the written language. In this sense, there are serious barriers for people who have difficulties interpreting and writing complex texts. Our previous studies [3] highlighted many difficulties people with low literacy face when searching and accessing information on the web. In this paper, we focus on an analysis of usability barriers for people with hearing loss when interacting with Web content. We aim to analyze the opinions, impressions, and scenarios faced by internet users with hearing loss.

In the paper, the problem (i.e., web usability for people with hearing loss) is analyzed from a Semiotic perspective. A study was conducted in the Deaf Service Center of the city of Macapá in Brazil with users with hearing loss. The users in the study have varying profiles and different (written) language skill levels. The analysis of the results was based on artifacts form Organizational Semiotics (OS) [4].In particular, we aimed to study communication aspects in all the levels of the semiotic framework presented in [4], i.e, physical, empirical, syntactic, semantic, pragmatic, and social aspects.

This paper is structured as follows: the second section defines key concepts used in this work, and presents the theoretical and methodological foundations taken from OS; the third section presents the study, including its context, subjects, and methods; the fourth section presents and discusses the results; and the fifth section concludes the paper.

\section{Concepts and Background}

There are several studies in accessibility and universal design literature that aim to understand how to provide a Web that is accessible for all. These studies research barriers and design solutions for the inclusion of people with, for example, low vision (e.g., [5, 6]) and the elderly (e.g., [7, 8, 9]). In this section, we focus on introducing key concepts adopted in the paper (subsection 2.1), and on presenting the theoretical background, the adopted methods, as well as previous works (subsection 2.2).

\subsection{Hearing Loss and Universal Usability}

Hearing loss can be understood as the reduction of sensitivity to sounds, as compared to that of the average person, as defined by the American National Standards Institute [10]. According to [11, p. 602] hearing loss is "an inability to hear specific frequencies at the appropriated intensity".

The deafness concept (a degree of Hearing impairment) is associated with the inability to understand speech even with amplification, i.e., the individual is impaired in processing linguistic information through hearing [11]. According to [12] "speech reception threshold" is the sound level at which 50 percent of a list of presented words are understood, and the "speech recognition score" is the percentage of words understood at $40 \mathrm{~dB}$ above the reception threshold.

Children with hearing impairment have a different process for learning how to read and write. This can be explained by the fact that the written language is strongly 
based on the spoken language (and sounds in general). There are many studies that analyze how to teach children with deafness [13]. The studies vary in their teaching strategy recommendations and have provided for advances in the area. Some institutions and associations are also dedicated to promoting literacy. Studies [13] also suggested that the written language can be considered a second language for many, as the first language is usually Sign Language.

In practice, there are many people who are born with hearing impairment and achieved high levels of literacy skills. However, language skills vary from person to person. Furthermore, we (with or without hearing loss) are continually learning and improving our language skills due to new knowledge and experiences.

The Web is an increasing and important source of information. In this scenario, the internet plays a central role in the development of new skills, which includes writing and reading. However, there are various barriers for the usage of the internet as a result of different personal needs, regardless of the need being associated with a physical impairment or not. Furthermore, the Web can be transformed into an opportunity for inclusion, and for people with low literacy skills to improve their abilities [3].

There are various Assistive Technologies (AT) for supporting meaningful interactions on the Web. AT solutions for users with hearing loss range from simple caption editors to complex video generators, which translate the written text into sign language. These AT solutions are certainly an important mechanism for including people with hearing loss on the Web. However, in addition to AT, there is a need for research to be developed in the field of design, which will probably require new AT solutions.

The challenges in the design include understanding the needs of the users, what are their difficulties during Web usage today, and their suggestions. This study can be done in a participatory and structured way so as to guarantee that the communication problems experienced can be properly studied from the users' perspective.

\subsection{Organizational Semiotics Methods}

OS can be understood as one of the "branches" of Semiotics developed by Peirce [14] and others. Organization is considered a social system in which people behave in an organized manner by conforming to a certain system of norms [4]. From this perspective, the Web can be studied as an organization.

Among the methods employed by the OS community is a set of methods known as MEASUR (Methods for Eliciting, Analyzing, and Specifying Users' Requirements) [15], which deals with the use of signs, their function in communicating meanings and intentions, and their social consequences. In the subset of MEASUR' methods known as Problem Articulation Methods (PAM), the analysts define system units that will be validated by stakeholders. Two of the PAM methods were adapted to be used in the context of this paper, the Semiotic framework (or Semiotic diagnosis) and the Evaluation framing (from the valuation framing).

By using the Semiotic framework we can conceptualize the Web system in six layers, from the system platform to the human information functions. In addition to 
syntactic, semantic, and pragmatic Semiotic layers, Stamper has added an additional three layers: physical, empiric, and social world. As defined in [4], each level of the semiotic framework can be described as follows:

1. Physical: signals, traces, physical distinctions, hardware, component density, speed, economics, ...

2. Empiric: pattern, variety, noise, entropy, channel capacity, redundancy, efficiency, codes, ...

3. Syntactic: formal structure, language, logic, data, records deduction, software, files, ...

4. Semantic: meanings, propositions, validity, truth, signification, denotations, ...

5. Pragmatic: intentions, communications, conversations, negotiations, ...

6. Social: beliefs, expectations, functions, commitments, contracts, law, culture, ...

The Semiotic framework can be used to understand, design, and analyze Web systems. For example, in Baranauskas et al. [16] the Semiotic framework was used to inspire a set of Inspection Guidelines used to evaluate interfaces of e-commerce applications.

The Evaluation framing method allows for the identification of the interests, questions, and problems of each stakeholder, so that possible solutions can be envisaged [17]. This method is an adaptation of the Valuation Framing method, as presented in Liu [4]. It can be used to reveal the cultural behaviors of the constituents in relation to the benefits and drawbacks of an action course.

In the Evaluation framing adopted in this paper, possible problems and solution are evaluated with each stakeholder according to three problem levels, which are based on the levels of the "organizational onion" as presented in [4]: Informal level there is a sub-culture in which meanings are established, intentions are understood, beliefs are formed, and commitments involving responsibilities are made, altered, and discharged; Formal level form and rule replace meaning and intention; and, Technical level part of formal system that is automated by a computer-based system.

In [17], for example, the Semiotic framework and Evaluation framing were adopted in participatory practices for the design of inclusive eGovernment systems. Previous works explain the potential for using Participatory Design (PD) with OS for the design of an inclusive Web interface.

\section{The Study}

This section outlines how the study was conducted. The subsection 3.1 presents details about the context of the study and the subjects, including the user's profile. The subsection 3.2 presents the method used in order to perform the study.

\subsection{Context and Subjects}

The study presented in this paper was conducted in the Deaf Service Center of the city of Macapá in Brazil - CAS (Centro de Atendimento ao Surdo). CAS develops practices that aim to train teachers in public schools, interpreters of Brazilian Sign 
Language, Libras' interprets, Libras' instructors, and other professionals that work with people with hearing loss. Furthermore, CAS also supports the public schools in the State of Amapá by providing courses and psychological assistance to students and their family. In the CAS staff, there are 25 professionals with hearing loss, including instructors, physicians, and physical therapists, as well as its director.

As shown in Table 1, a total of 21 users with high levels of hearing loss participated in the study presented in this paper. All them were fluent in Libras and 19 (90\%) had lip-reading skills; however they had different skill levels in Portuguese language. Considering their educational levels, 14 participants held university degrees and 7 held high school degrees. Their ages ranged from 14 to 44 years old. All the participants declared that they use the internet frequently (more than once a week), nevertheless most of them also declared that they have serious difficulties in using it. The participants have higher educational levels than the average Brazilian population. They also have high proficiency in sign language.

Table 1. Participants of the Study

\begin{tabular}{|c|c|c|c|c|c|c|c|}
\hline$\underline{N^{o}}$ & Name & Age & Educational level & $\frac{\text { Use Internet }}{\text { Frequenthy }}$ & $\begin{array}{c}\text { Sign } \\
\text { Language }\end{array}$ & $\frac{\text { Level of hearing }}{\underline{\text { loss }}}$ & $\underset{\text { readipg }}{\underline{\text { reading }}}$ \\
\hline 01 & A.B.O. & 28 & $\begin{array}{l}\text { Undergraduate (information } \\
\text { systems) }\end{array}$ & Yes & Yes & Profound & No \\
\hline 02 & D. S. & 32 & $\begin{array}{l}\text { Undergraduate (information } \\
\text { systems) }\end{array}$ & Yes & Yes & Profound & Yes \\
\hline 03 & C. A. M. B. & 40 & $\begin{array}{l}\text { Undergraduate (information } \\
\text { systems) }\end{array}$ & Yes & Yes & Profound & No \\
\hline 04 & C. C. S. & 26 & Undergraduate (pedagogy) & Yes & Yes & Profound & Yes \\
\hline 05 & D. E. L. & 28 & Undergraduate (pedagogy) & Yes & Yes & Profound & Yes \\
\hline 06 & F. & 28 & Secondary & Yes & Yes & Profound & Yes \\
\hline 07 & G. L. C. & 25 & Graduate (pedagogy) & Yes & Yes & Moderate & Yes \\
\hline 08 & J. & 25 & Secondary & Yes & Yes & Profound & No \\
\hline 09 & V.R. & 39 & Undergraduate (pedagogy) & Yes & Yes & Profound & Yes \\
\hline 10 & J.R. C. & 32 & Undergraduate (pedagogy) & Yes & Yes & Profound & Yes \\
\hline 11 & $\begin{array}{l}\text { A. -Teacher in } \\
\text { CAS }\end{array}$ & 32 & Graduate ( pedagogy) & Yes & Yes & $\begin{array}{l}\text { Profound (hearing } \\
\text { loss after age } 8 \text { ) }\end{array}$ & Yes \\
\hline 12 & Rf. P. & 26 & Undergraduate ( pedagogy) & Yes & Yes & Profound & Yes \\
\hline 13 & Ro. P. & 26 & Undergraduate ( pedagogy) & Yes & Yes & Profound & Yes \\
\hline 14 & V.A. & 28 & Undergraduate ( pedagogy) & Yes & Yes & Profound & Yes \\
\hline 15 & J.A.P.B. & 31 & Undergraduate ( pedagogy) & Yes & Yes & $\begin{array}{l}\text { Profound (hearing } \\
\text { loss after age } 7 \text { ) }\end{array}$ & Yes \\
\hline 16 & $\begin{array}{l}\text { M.J.N.C.B. } \\
\text { CAS Director }\end{array}$ & 44 & Graduate (pedagogy) & Yes & Yes & Profound & Yes \\
\hline 17 & T.N.C. & 15 & Primary school student & Yes & Yes & Severe & Yes \\
\hline 18 & A.S.C. & 23 & Secondary & Yes & Yes & Profound & Yes \\
\hline 19 & M.L.M. & 16 & Secondary school student & Yes & Yes & Profound & Yes \\
\hline 20 & L.B.C. & 26 & Secondary & Yes & Yes & Profound & Yes \\
\hline 21 & R.S.C. & 17 & Secondary school student & Yes & Yes & Profound & Yes \\
\hline
\end{tabular}

\subsection{Materials and Methods}

As mentioned before, the methods employed in the study are based on OS and UD. Participation was encouraged during all activities. The study was organized and conducted in two steps, as follows:

First Step

During the first step a questionnaire was applied with open-ended questions that asked the participants about previous experiences and difficulties when using the Web. The users were also asked to write the answers in Portuguese. An interpreter 
translated the questions to Libras, and answers from Libras to Portuguese, only when requested by the participants. The questionnaire was composed of seven questions, as follows: (1) Do you use the internet to search for information? (2) Do you use social networks? Which ones? (3) Can you easily navigate through internet sites? What are your difficulties? (4) Can you easily understand search results? Do you find the appropriated results? (5) Which tasks do you perform daily when using computers? (6) Do you understand the language used on the internet? (7) Observations and Comments.

In the first step, participants were also encouraged to describe situations and scenarios where they experienced difficulties when using the internet in the past. These experiences could be recorded on post-its using the written language, or could be explained with the use of the interpreter for translation.

Second Step

During the second step, the designers aimed to elicit a set of problems, and discuss solutions during participatory evaluation sessions. The method was inspired by Semiotic Framework and Evaluation Framing artifacts.

The users were asked to discuss situations related to physical, empiric, syntactic, semantic, pragmatic and social aspects. Firstly, the designer (with the Libras interpreter) presented the situations to the participants and asked them to describe a usage scenario; for instance, the use of a search mechanism, web commerce, or a social network. After that, they were asked to report problems, difficulties, and expectations.

During these discussions, the semiotic framework was used as a guide for structuring the questions about the scenarios. However, this method was not formally presented to the participants. The problems and solutions were discussed using the evaluation framing as a guide.

At the end, the results were tabulated, contrasted, and analyzed in pairs. The focus of the analysis was on qualitative results, including the opinions expressed by the participants. The next section presents and discusses the results.

\section{$4 \quad$ Results and Discussion}

In the first step, the majority of the answers provided on the questionnaire were short and direct; in many cases the answers were "yes"/"no", even for the open-ended questions. However, some significant answers were collected, such as:

- Answer to question 1: "I like to search the Web, but I have difficulty understanding some results."

- Answer to question 1: "I like to search for content related to people with hearing loss."

- Answer to question 2: "I use Facebook, but I have to learn how to use it better."

- Answer to question 3: "Yes. I have difficulty since the meaning of the words are different ..."

- Answer to question 4: "Not too much ..." 
- Answer to question 5: "Information, job opportunities, and to communicate with my friends."

- Answer to question 6: "In my opinion the majority of people with hearing loss have difficulty understanding the internet due to the difficulty in understanding the meaning of the written language."

- Answer to question 6: "I have difficulty understanding big texts, so I request support from an interpreter to explain the meaning of the words."

- Answer to question 7: "I would like for the Libras alphabet to be embedded in the computer (operational system)."

- Answer to question 7: "I would like visual information/drawings associated with the words."

- Answer to question 7: "It is important to have drawings within the text."

After answering the questions, the participants were invited to describe difficulties when accessing the Web. Figure 1 presents six selected scenarios described in Portuguese (written language) without the interpreter's intervention. In general, the perceptual aspects were not identified as the dominant problem. The results highlighted the importance of taking into account semantic, pragmatic, and social aspects for proving a fully usable Web. Figures $1 \mathrm{~A}$ to $1 \mathrm{~F}$ describe the perspective of six users: (A) the participant considered the Web interesting, but highlighted his difficulty remembering passwords; (B) the user described that he needs a course to learn how to best use the Web, as well as emphasized its importance for finding a job; (C) the user considered that she has not learned everything that she needs in order to use the internet properly, and that she has the desire to learn more; (D) the user emphasized that she lost her MSN password, and that she does not know how to recover it; (E) the user stressed the difficulty in searching and using the correct keywords on Facebook; (F) the user wrote about the difficulty in understanding the written language on the Internet. He highlighted that people with hearing loss's first language is sign language, and some words have different meanings.

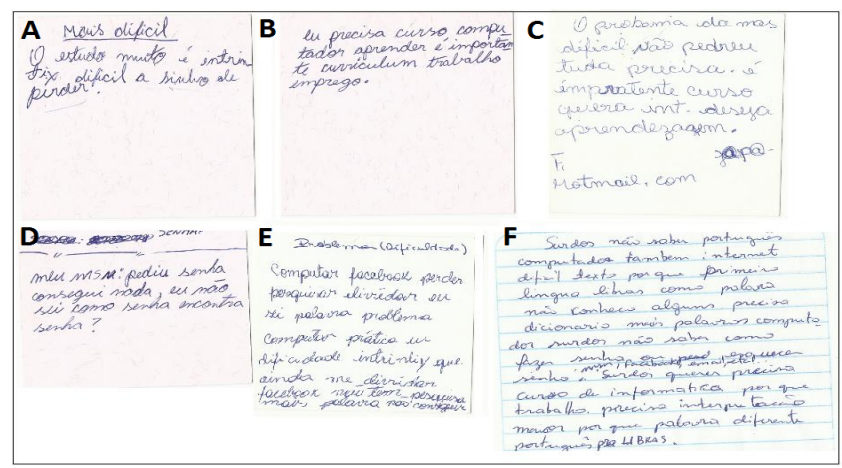

Fig. 1. Difficulties pointed out by the participants 
During the second step, issues from the physical to social level were elicited using the Semiotic framework as a guide. The following items briefly describe aspects that were repeatedly cited by the participants during the practice:

1. Physical. The main problem pointed out is due to the use of radio access network as the hardware solution for proving internet (at home) in their city, instead of cable or fiber based solutions.

2. Empirics. They complained about the quality of the internet in their city. This is a barrier to communicating with others using multimedia (video) resources. The links are instable, have high-latency, and low Bandwidth.

3. Syntactic. They emphasized that the grammatical structure of the written language is difficult to assimilate by people with hearing loss. They frequently do not use articles and prepositions, as well as have difficulty with verb conjugation in the Portuguese language. The words are frequently associated with their purpose as in Libras, instead of the sounds. The "Internet slang" (or Cyber-slang) is a barrier, once (at least in Portuguese) formal grammatical rules that can be learned (memorized) are substituted by phonetic based constructions in the "Internet slang".

4. Semantics. They associate reading and writing with the meaning of words in Libras, and sometimes have difficulty understanding synonymous and polysemous words. In this sense, the use of the word with different meanings in the context of the internet may constitute a barrier. Many participants emphasized their difficulty understanding long texts, and that sometimes they need an interpreter to help to understand the text.

5. Pragmatics. The participants emphasized that they use the internet as a source of information, of news, and for communicating with friends. The majority of the participants also highlighted that they intend to improve their ability to use the computer and the internet They also see the internet as an important source of information about hearing loss.

6. Social. Many participants stressed that internet skills nowadays are considered important when applying for good jobs. They also emphasize the importance of the social networks. Some participants expressed the importance of socially interacting with, and meeting, other people with hearing loss.

After this conversation, problems and solutions were discussed using the evaluation framing as a guide. Figure 2 summarizes the questions and problems, as well as solutions and ideas elicited by the participants. Each problem was categorized according to informal, formal, and technical levels. However, some problems may have implication in two or more levels. The solutions and ideas were categorized at the same level as the problem that they intend to solve. 


\begin{tabular}{|c|c|c|}
\hline & Questions and Problems & Solutions Ideas \\
\hline $\begin{array}{c}\text { Informal } \\
\text { level }\end{array}$ & $\begin{array}{l}\text { - In some cases the support of an interpreter is necessary in } \\
\text { order to give context to words and synonyms } \\
\text { - In some cases, the meanings can be inferred only if visual } \\
\text { information is available (e.g., a photo with the text) } \\
\text { - Many participants considered that training is necessary } \\
\text { - Difficulty using chat. Many people have difficulty reading } \\
\text { what was written by people with hearing loss } \\
\text { - There are many problems understanding the written content } \\
\text { on the web } \\
\text { - Limited Portuguese vocabulary } \\
\text { - Internet slang terms are harder to understand }\end{array}$ & $\begin{array}{l}\text { - In large sites (e.g. e-government and e-commerce) } \\
\text { provide online interpreter support } \\
\text { - Use meaningful images with complex texts } \\
\text { - To provide online training programs (with sign } \\
\text { langue instructions) } \\
\text { - Provide as much as possible video options in the } \\
\text { chat and forum tools } \\
\text { - Provide mechanisms to stimulate the learning of } \\
\text { new words by associating them with sign language } \\
\text { explanations } \\
\text { - Include more images associated with the text }\end{array}$ \\
\hline Formal level & $\begin{array}{l}\text { - Content that is not produced according to the formal } \\
\text { grammatical rules are even more difficult to understand } \\
\text { - Difficulties following the grammatical rules } \\
\text { - Difficulties understanding synonymous and polysemous } \\
\text { - Some of them have limited vocabulary in the written } \\
\text { language }\end{array}$ & $\begin{array}{l}\text { - Produce content using clear and formal language } \\
\text { - Provide better grammatical support in the text field } \\
\text { - For each written word provide examples of use (in } \\
\text { phases) }\end{array}$ \\
\hline $\begin{array}{l}\text { Technical } \\
\text { level }\end{array}$ & $\begin{array}{l}\text { - Low bandwidth } \\
\text { - Sites less structured with big text are usually more } \\
\text { problematic } \\
\text { - In many cases, there is no multimedia/visual alternative } \\
\text { content available } \\
\text { - Few websites have Libras content }\end{array}$ & $\begin{array}{l}\text { - Automatic text to Libras translation } \\
\text { - Provide simplified text alternatives } \\
\text { - Associate words with other meanings and } \\
\text { synonyms through visible in "hints" } \\
\text { - Include more images associated with the text } \\
\text { - Links must suggest what they do } \\
\text { - Structure the website in a logical way }\end{array}$ \\
\hline
\end{tabular}

Fig. 2. Questions and Ideas elicited by the participants

Some solutions and ideas presented in Figure 2 are easy to implement (e.g., include more images associated with the text) or are well-known design practices (e.g., structure the website in a logical way); while other solutions demand intensive investigation (e.g., automatic text to Libras translation).

We judged that the results found during both steps are not conclusive and do not have statistical significance (as there were only 21 participants).On the other hand, they identify important aspects to be considered in the design, as well as issues that have to be deeply investigated. These issues include how to provide design solutions that are accessible for people with hearing loss at the same time that they should promote the long term learning of the written language.

\section{Conclusion}

Many universal usability studies aim to promote a Web that is accessible and usable for all. These studies aim to analyze and remove usage barriers for people with a variety of needs. However, the barriers for people with hearing loss go beyond the perceptual ones (i.e., the use of audio based content), resulting in the need for investigating multifaceted solutions. In fact, sites with complex, long, or ill structured text cannot be considered fully usable by people with hearing loss.

We conducted an investigation of the barriers for Web users with hearing loss. In this investigation we adopted OS theories and methods as a basis. The paper presents a study with 21 participants performed in two steps: (1) questionnaire and situation/scenario description, and (2) participatory evaluation of problems and barriers for using the Web. The results pointed to a set of problems, as well as solutions, to be investigated in future studies. Future works should include a deeper analysis of the semantic aspects, and the construction of prototypes according to the elicited ideas. 


\section{References}

1. Shneiderman, B.: Universal Usability. Communications of the ACM 43(5), 85-91 (2000)

2. Oishi, N., Schacht, J.: Emerging treatments for noise-induced hearing loss. Expert. Opin. Emerg. Drugs 16(2), 235-245 (2011)

3. Reis, J.C., Bonacin, R., Baranauskas, M., Cecilia, C.: Addressing Universal Access in Social Networks: An Inclusive Search Mechanism. In: Universal Access in the Information Society. Springer (February 2013), doi:10.1007/s10209-013-0290-7

4. Liu, K.: Semiotics in information systems engineering. Cambridge University Press (2000)

5. Yang, Y.-F., Hwang, S.-L.: Specialized design of web search engine for the blind people. In: Stephanidis, C. (ed.) HCI 2007. LNCS, vol. 4556, pp. 997-1005. Springer, Heidelberg (2007)

6. Sagata, Y., Watanabe, M., Asano, Y.: VoiceBlog for blind and weak-eyed people. In: Stephanidis, C. (ed.) HCI 2007. LNCS, vol. 4556, pp. 961-969. Springer, Heidelberg (2007)

7. Dinet, J., Brangier, E., Michel, G., Vivian, R., Battisti, S., Doller, R.: Older people as information seekers: Exploratory studies about their needs and strategies. In: Stephanidis, C. (ed.) HCI 2007. LNCS, vol. 4554, pp. 877-886. Springer, Heidelberg (2007)

8. Hellman, R.: Universal design and mobile devices. In: Stephanidis, C. (ed.) HCI 2007. LNCS, vol. 4554, pp. 147-156. Springer, Heidelberg (2007)

9. Chadwick-Dias, A., Bergel, M., Tullis, T.S.: Senior surfers 2.0: A re-examination of the older web user and the dynamic web. In: Stephanidis, C. (ed.) HCI 2007. LNCS, vol. 4554, pp. 868-876. Springer, Heidelberg (2007)

10. ANSI, American National Standard Specifications for Audiometers. The Institute, $22 \mathrm{p}$. (1969)

11. Harfi, H.A., Nazer, H.M., Stapleton, F.B., Oh, W., Whitley, R.J.: Textbook of Clinical Pediatrics, vol. 1. Springer (2011)

12. Isaacson, J.E., Vora, N.M., Milton, S.: Differential Diagnosis and Treatment of Hearing Loss. Am Fam. Physician 68(6), 1125-1132 (2003)

13. Power, D., Leigh, G.R.: Principles and practices of literacy development for deaf learners: a historical overview. Journal of Deaf Studies and Deaf Education 5, 3-8 (2000)

14. Peirce, C.S.: Collected Papers. Harvard University Press, Cambridge (1931-1958)

15. Stamper, R.K.: Social Norms in requirements analysis - an outline of MEASUR. In: Jirotka, M., Goguen, J., Bickerton, M. (eds.) Requirements Engineering, Technical and Social Aspects, Academic Press, New York (1993)

16. Baranauskas, M.C.C., Liu, K., Chong, S.: Web site interfaces as representamen of organizational behavior. In: Gazendam, H.W.M., Jorna, R.J., Cijsouw, R.S. (eds.) Dynamics and change in organizations: Studies in organizational semiotics, vol. 1, pp. 63-88. Kluwer Academic, Dordrecht (2003)

17. Bonacin, R., Melo, A.M., Simoni, C.A.C., Baranauskas, M.C.C.: Accessibility and interoperability in e-government systems: outlining an inclusive development process. Universal Access in the Information Society (Print), vol. 9, pp. 17-33 (2010) 